Vol. 25, No. 1, pp. 34-39.

19. Lee S.D., Jeong J.C., Chung J.M. Secondary surgery for vesicoureteral reflux after failed endoscopic injection: comparison to primary surgery. Investigative and Clinical Urology, 2016, No. 57, pp. 58-62.

20. Yılmaz İ., Peru H., Y1lmaz F.H., Sekmenli T., Çiftçi İ., Kara F. Association of vesicoureteral reflux and renal scarringin urinary tract infections. Archivos Argentinos de Pediatría, 2018, Vol. 116, No. 4, pp. 542-547.

\section{ХУЛОСА}

Х. Ибодов, Т.Ш. Икромов, Х.М. Мираков, К.М. Сайёдов, Р. Рофиев, С.К. Асадов

\section{ТАБОБАТИ РЕФЛЮКСИ ВЕЗИКОУРЕТЕРАЛИ ДАР КУДАКОН}

Мақсади омӯзиш. Омӯзиши самаранокии ислохи эндоскопии рефлюси везикоуретералй дар кӯдакон бо истифода аз маводи синтетикии хачмбардор.

Мавод ва усулхои тадқиқот. Дар давраи аз соли 2016 то 2020 мо натичахои табобати 63 кӯдаки рефлюкси везикоуретералиро омӯхтем. Кўдакон аз 6 моха то 17 сола буданд. Дарачаи VUR: дарачаи I (3.1\%), дарачаи II (25.3\%), дарачаи
III 30 (47.6\%), дарачаи IV 13 (21.98\%), дарачаи V 2 (3.1\%). Маълум шуд, ки аз 63 бемори мархилаи 1. дар 26 (41,3\%), II ст. - дар 16 (25,4\%); Моддаи III - дар 13 (20,6\%); IV. - дар 8 (12,7\%), ва беморони гирифтори Вст. - CKD вучуд надошт. VUR-и яктарафа дар 45 кӯдак (71,4\%), VUR-и дутарафа дар 18 (28,5\%) кӯдакон мушохида шудааст. Коррекцияи эндоскопии intravesical VUR бо усули зери пардаи луобй тазриқи «Dam +» гузаронида шуд.

Натичахои тадқиқот ва мухокима. Натичахои тадқиқоти моро чамъбаст карда, бояд қайд кард, ки дар робита бо қать кардани сироятхои руддаи пешоб, рафъи вайроншавии ихрочи пешоб аз холиб, бехтар кардани вазифаи гурда пас аз ислохи VUR бо истифода аз Dam + натичахои мусбат ба даст оварда шудаанд. Натичахои мусбии ислохи PMR 75.01\%-ро ташкил медиханд.

Хулоса. Ислохи эндоскопии VUR яке аз усулхои муассиртарин ва осеби камтари табобат мебошад. Истифодаи маводи синтетикии биологии мувофиқ «Дам +» дар ислохи рефлюкси везикоуретералй ба ноил шудан ба натичахои мусбат мусоидат менамояд.

Калимахои калиди: дахолати эндоскопй, моддахои хачмй, рефлюкси везикоуретералй, кӯдакон.

\title{
Н.Т. Курбанов
}

\section{ОСОБЕННОСТИ СЕКСУАЛЬНОГО ПОВЕДЕНИЯ МОЛОДЕЖИ, ДЕТЕРМИНИРУЮЩИЕ РОСТ ЗАБОЛЕВАЕМОСТИ ИНФЕКЦИЯМИ, ПЕРЕДАЮЩИМИСЯ ПОЛОВЫМ ПУТЕМ, В РЕСПУБЛИКЕ ТАДЖИКИСТАН}

\section{ГУ «НИИ профилактической медицины Таджсикистана» МЗ и СЗНРТ}

Курбонов Назарали Талабович - соискатель ГУ «НИИ профилактической медицины в Таджикистана» М3 и СЗНРТ, тел.: 907072013; «kurbonov-6969@mail.ru»

Цель исследования. Выявить особенности сексуального поведения молодежи, обуславливающие распространение инфекций, передающихся половым путем.

Материалы и методы исследования. По специально разработанной анкете проведен опрос 500 лии мужского и женского полов, относящихся к различным социальныл слоям населения в возрасте $18-30$ лет и находящихся в 4 районах республиканского подчинения. При этом социологический опрос основьвался на типической выборке названной возрастной группь. Ответы на поставленные вопросы подвергли статистической обработке с использованием пакетов MS Office 2007 г.

Результаты исследования и их обсуждение. Установлено, что соответствующая информированность респондентов об инфекциях, передаюшихся половым путем, и о мерах их профилактики остается на очень низком уровне. Более $21 \%$ из них имеют регулярные сексуальные контакты, причем как минимум каждый пятый не связывает с этим возможную реализацию риска заражения ИППП/ВИЧ/СПИДом.

Среди ИППП наиболее часто встречаются гонококковая, трихомонадная, хламидийная, микроуреаплазмен- 
ная инфекция, а также бактериальный вагиноз. Около 17\% молодых людей считают, что в случае заражения этими болезнями за медицинской помощьью обращуаться будут только к своим знакомымм врачам или средним медицинским работникам.

Заключение. Доподлинно известно, что сегодня в молодежной среде приемлемы фактически все модели сексуального поведения и все типы сексуальных отношений. Однако, в Таджикистане существует некоторые особенности сексуального поведения молодежи (многоженство и развитие института гражданского брака). Установлен низкий уровень знаний и необходимость повышения осведомленности подростков и молодежи о негативных последствиях рискованного сексуального поведения.

Ключевые слова: репродуктивное поведение, молодежь, образ жизни, факторы риска, инфекции, передающиеся половым путем.

\section{N.T. Kurbanov}

\section{FEATURES OF SEXUAL BEHAVIOUR OF YOUNG PEOPLE THAT DETERMINE THE INCREASE IN THE INCIDENCE OF SEXUALLY TRANSMITTED INFECTIONS (STI) IN THE REPUBLIC OF TAJIKISTAN}

SI «Research Institute of Preventive Medicine of Tajikistan» of Ministry of Health and Social Protection of the Population of the Republic of Tajikistan, Dushanbe, Tajikistan

Kurbonov Nazarali Talabovich - research associate in the State Institution "Research Institute of Preventive Medicine in Tajikistan" of the Ministry of Health and Social Protection, tel.: 907072013, "Kurbonov-6969@mail.ru”.

Aim. To identify the features of the sexual behavior of young people that cause the spread of sexually transmitted infections.

Material and methods. A questionnaire was developed and a survey was conducted among 500 men and women that belong to various social groups of the population. The age of participants was 18 - 30 years and they were coming from 4 districts of republican subordination. The survey was based on a typical sample of the mentioned age group. Collected data were statistically processed using MS OFFICE 2007 packages.

Results and discussion. It was found that the awareness of respondents about sexually transmitted infections and measures for their prevention remains at a very low level. More than $21.0 \%$ of respondents have active sexual life, and at least one in five does not associate this with the possible realization of the risk of contracting STIS / HIV / AIDS. About $17.0 \%$ of young people believe that if they become infected with these diseases, they will seek medical help only from their friends, physicians that they are familiar with, and paramedics.

Conclusion. It is known for a fact that virtually all models of sexual behavior and all types of sexual relationships are present among young people today. However, in Tajikistan, there are certain features of the sexual behavior of young people (polygamy and civil marriage). A low level of knowledge and the need to raise awareness among adolescents and young people about the negative consequences of risky sexual behavior have been established.

Keywords: reproductive behavior, youth, lifestyle, risk factors, sexually transmitted infections.

Актуальность. Со второй половины ХХ века и до настоящего времени человечество сталкивается с массовой распространенностью инфекций, передающихся преимущественно половым путем, причем во множественном числе $[2,5,8]$.

В структуре факторов, формирующих здоровье молодежи особенно подросткового возраста, большое значение имеет такой фактор, как поведение, обусловленное растущим радикализмом и умственным «инфантилизмом» ${ }^{1}$ в некоторых странах. Особую актуальность поведенческий фактор приобрел в связи с ростом подверженности подростков инфекциями, передающимися половым

1. В переносном смысле - особенность в развитии, проявление наивного подхода в отношениях, быту и в жизни. путем (ИППП).

Так, среди молодых людей до 25 лет ежегодно происходит более 100 миллионов новых заражений, исключая ВИЧ, представляя глобальную угрозу здоровью людей. Всего за названный период в мире было зарегистрировано 340 млн. новых случаев заболеваемости ИППП среди молодых людей $[1,3,6,7]$. Проблемы сексуального и репродуктивного здоровья подростков и молодежи, прежде всего, обусловлены низким уровнем репродуктивного образования, ранними браками, ростом гинекологической и венерической заболеваемости, беременностью и родами в юном возрасте, конфликтами и психологической напряженностью в семье $[2,6,8]$.

Кроме того, социальная значимость определя- 
ется снижением трудовой активности, супружеской неверностью, бесплодием, развитием психологического конфликта, домашним насилием и распадом семьи $[1,4,5,7]$. Не исключено, что от уровня здоровья подростков зависит реализация их жизненных планов, стремление к социальному развитию, в т.ч. к созданию семьи и рождению детей, предопределяющих положение всей страны.

Учитывая напряженную эпидемиологическую ситуацию, особенно в постсоветских странах, вызванную распространением ИППП, руководство BO3 в рамках стратегии «Здоровье для всех в 21 веке» ещё в 1998 г. обратилось к правительствам стран, международным и неправительственным организациям с призывом объединить усилия в борьбе с названными заболеваниями.

Данная инициатива ВО3 нашла поддержку среди большинства членов ООН, в т.ч. и в Республике Таджикистан, где при содействии основных партнеров разрабатываются и реализуются Национальные программы по профилактике и борьбе с социально значимыми заболеваниями на период до 2030 года.

В настоящее время в нашей стране уже имеются Национальные программы по борьбе с туберкулезом и ВИЧ/СПИД на период 2021-2025 г. Однако, к сожалению, в республике до сих пор нет Национальной программы по профилактике и борьбе с ИППП.

Разработка и осуществление этой Программы позволили бы в государственном масштабе реализовать комплекс необходимых лечебных и профилактических мероприятий в данном направлении. Поэтому необходимо ускорить работу по подготовке Национальной программы по профилактике и борьбе с ИППП на период до 2030 года.

В обстановке мирового финансового кризиса, роста бедности, вынужденной внешней трудовой миграции наблюдается «взрыв» сексуальной активности, обусловленной прежде всего социальнокультурными факторами, уровнем воспитания в семье и школе.

При этом обычными стали добрачные половые связи, аборты, рост подросткового материнства, заболеваний, предающихся половым путем, патологий репродуктивных органов $[1,4,5]$. Однако в новых социально-экономических условиях широкое распространение ИППП характерно не для всей молодежи. Для определенной ее части конкретные условия жизни, уровень образования и воспитания зависят от характера усвоенных в процессе взросления норм поведения.
Существенно возросли проблемы здорового образа жизни, сексуального и репродуктивного здоровья среди социально уязвимых групп населения, в т.ч. молодежи, что и определило цель настоящего исследования.

Цель исследования. Выявить особенности сексуального поведения молодежи, обуславливающие распространение инфекций, передающихся половым путем.

Материалы и методы исследования. По специально адаптированной анкете с 1 октября по 15 ноября 2019 года проведен социологический опрос среди 500 молодых людей мужского и женского пола, которые относились к различным слоям гражданского общества, с различными уровнями образования, трудоустройства и семейного положения, в 4 густонаселенных сельских районах республиканского подчинения: Рудаки, Вахдате, Гиссаре и Шахринау.

Из общего количества респондентов - 296 (59,2\%) мужчин и 204 (40,8\%) женщины, соответственно женатыми оказались 122 (41,2\%), замужними - 80 (39,2\%) человек. При этом большинство респондентов имели среднее, высшее, незаконченное высшее или среднее специальное образование.

Исследовалась типическая выборка лиц возрастной категории от 18 до 30 лет. Анализ анкетных ответов проведен ретроспективным, клинико-статистическим и социально - аналитическим методом.

Результаты исследования и их обсуждение. Установлено, что из 134 студентов ВУЗов 25 (18,6\%) человек имели опыт половой жизни, из 108 студентов ССУЗов - 16 (14,8\%) человек; из 202 лиц имели половые связи до замужества или женитьбы - 64 (31,6\%) человека (Рис 1.). Все $92(18,4 \%)$ ученика средних школ опыта половой жизни не имели или на соответствующий вопрос не ответили.

Рост общей заболеваемости подростков и молодежи обусловлен такими социальными факторами, как: низкая занятость, безработица и бедность, нехватка продуктов первой необходимости, недоступность медицинских услуг; рост преступности и бытового насилия; зависимость от азартных и компьютерных игр, наркотиков, низкая адаптация сельской молодежи к городским условиям жизни, нередко приводящими к ранней беременности, разводам, алкоголизму, проституции, табакокурению, росту инфекций, передающихся половым путем, и т.д. 


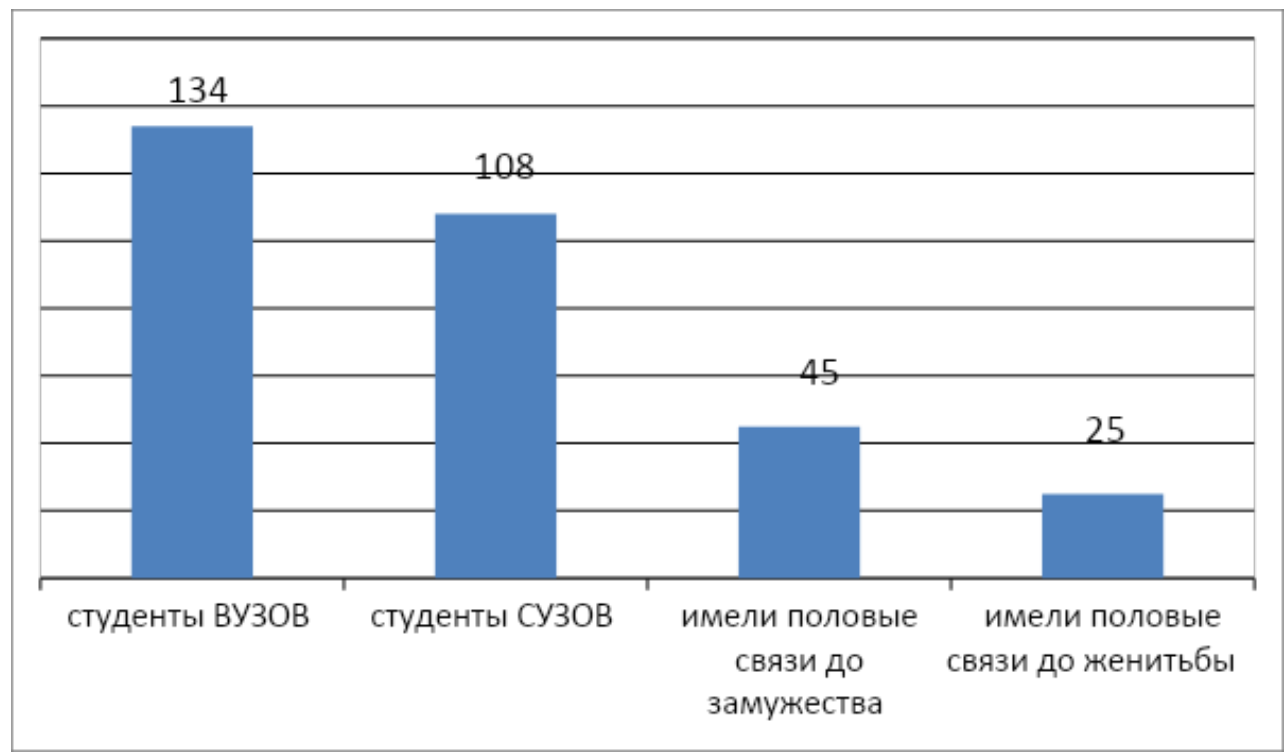

Рис. 1 Распределение респондентов по опыту половых связей (в обс. числах).

Факторами риска распространения ИППП в молодежной среде являются: ранее начало половой жизни, промискуитет и низкий уровень использования контрацепции. Употребление алкоголя и психотропных препаратов накладывают свой отпечаток на их сексуальное поведение.

Опасность многих ИППП заключается в их скрытом течении, особенно в инкубационном и продромальном периодах, в результате возможности широкого распространения.

Следует напомнить, что наиболее часто встречаются такие ИППП: сифилис, гонорея, урогенитальный хламидиоз, шанкроид, паховая гранулема (донованоз), хламидийная лимфогранулема, урогенитальный трихомониаз, герпетическая вирусная инфекция, анально-генитальные бородавки.

Половым путем также передаются вирус иммунодефицита человека (ВИЧ), вирус простого герпеса (ВПГ), вирус папиломы человека (ВПЧ), вирусы гепатитов В и C, а также некоторые паразитарные инфекции (фтириаз и чесотка), контагиозный моллюск, амебиаз и другие.

Названные заболевания относятся к наиболее ярко выраженным «социальным болезням» и обычно имеют максимально широкое распространение в период экономической нестабильности, низкой занятости лиц активного трудового возраста, безработицы, бедности.

Так же претерпевает изменение структура наиболее часто встречающихся ИППП за счет роста удельного веса заболеваний, которые чаще вызываются хламидиями и микоплазмами, чем гонококками.

За последние 10 лет заболеваемость сифи- лисом и гонореей в Таджикистане снизилась до уровня показателей 3,3-3,5 на 100 тыс. населения, однако заболеваемость другими ИППП остается высокой, как среди взрослого населения, так и среди молодежи.

Таким образом ИППП ложатся тяжелым бременем на бюджеты как домохозяйств, так и системы здравоохранения в странах со средним и низким уровнями доходов, негативно влияя на общее благополучие и развитие людей.

Установлено, что 29 (9,84\%) лиц мужского пола прибегают к курению сигарет или насвая, среди девушек таких было всего 14 (6,9\%). Алкоголь употребляли $75(25,34 \%)$ юношей и 16 $(7,84 \%)$ девушек, причем в каждом четвертом случае - по праздникам и семейным торжествам.

Среди учащихся старших классов, в т.ч. окончивших в них обучение, студентов ВУЗов и ССУЗов начало половой жизни совпадает с исполнением 18 лет в 4,1\% случаев, 19 лет - в 5,0\% случаев, 20 лет - в $6,1 \%$ случаев, 21 года- в $10,6 \%$ случаев и 22 лет - в 15,5\% случаев. Как показывают результаты исследования, респонденты раньше начинают половую жизнь, не всегда зная о методах контрацепции и часто не проходят регулярные обследования.

При этом 21,0\% респондентов имели постоянного полового партнера (муж, жена и лица, состоящие в гражданском браке). В то же время 10,3\% студентов учебных заведений перенесли ИППП, причем в $25,0 \%$ случаев заболевания не обращались в лечебно-профилактические учреждения, занимаясь самолечением.

Самолечение и неполноценное лечение боль- 
ных - наиболее частые причины роста заболеваемости среди лиц активного репродуктивного возраста, значимость которых существенно растет, особенно в бедных и развивающихся странах.

Установлено, что $16,8 \%$ респондентов в случае заражения ИППП не будут обращаться в лечебнопрофилактические учреждения и, скорее всего, станут лечиться у знакомого врача или медсестры, что приводит к развитию хронических форм некоторых заболеваний.

К развитию хронических форм заболеваний ИППП и факторов, обуславливающих тяжесть их течения, приводят несовершенство этапов оказания медицинской помощи, на первом месте из которых стоит профилактика.

Из общего числа мужчин, в т.ч. студентов ВУЗов, в период летних каникул в 2018 и 2019 годах находились в трудовой миграции 65 (21,9\%) человек, в том числе $30(10,1 \%)$ из них имели случайные половые связи.

Этому способствует сексуальная активность молодых людей, практикующих разнообразие половых контактов со случайными партнерами, недостаточное использование контрацептивных средств, что объясняет значительную распространенность среди них инфекционных заболеваний, передающихся половым путем.

Выявлено, что немногим более $29,0 \%$ студентов высших и средних специальных учебных заведений имели информированность о механизме передачи инфекций, передающихся половым путем. В 26,0\% случаев респонденты мужского и женского полов указали на незнание ответов на вопросы об их индивидуальной профилактике. При этом средства контрацепции использовали всего $33,8 \%$ респондентов.

Среди выше названных наиболее значимых проблем репродуктивного здоровья следует считать основными сохранение в молодежной среде таких явлений, как раннее начало половой жизни и низкая санитарная культура. Высокие показатели заболеваемости ИППП в молодежной среде связаны с особенностями поведенческих характеристик подрастающего поколения, особенно в условиях трудовой миграции.

Анализ ситуации свидетельствует, что в Республике Таджикистан доступ к охране репродуктивного здоровья подростков и молодежи недостаточен из-за слабой системы медицинского обслуживания, высокой стоимости и низкого качества оказываемых услуг, включая санитарнопросветительную работу среди населения горных местностей, а также отсутствия мониторинга и оценки работы учреждений первичного звена здравоохранения.

К тому же сексуальность, как неотъемлемая часть полноценного человеческого бытия, остается исключительно личной и уникальной сферой поведения с многочисленными социально-культурными табу и правилами, что затрудняет ее открытое и свободное обсуждение.

Самым фундаментальным барьером в Таджикистане, по нашему мнению, было и остается негласное табу на тему сексуальных отношений, которые воспроизводится в семье и сфере образования.

Для большинства людей сопротивление в отношении изучения полового поведения представляют глубокосидящие страхи и сомнения в отношении их личной жизни. При этом, воссоздавая стыдливый образ, навязанный окружающими, молодые люди упускают важную и содержательную информацию, касающуюся их репродуктивного здоровья.

Более того, традиционно лица, заразившиеся ИППП, стараются скрыть факт заболевания от близких и друзей, так как боятся стигматизации и осуждения окружающих. Пропаганда основ здорового образа жизни, в т.ч. половое воспитание должно идти неразрывно с социальными процессами, которые происходят вокруг подростков и молодежи.

Несмотря на разработку и внедрение в практику работы образовательных учреждений различных программ профилактики заболеваний и повышения культуры здоровья, результативность их остается очень низкой. В связи с этим возникла необходимость расширения образовательных программ с использованиями инновационных технологий в работе по улучшению соответствующей осведомленности подростков и молодежи.

Таким образом, необходима работа по мотивированности молодежи к сохранению репродуктивного здоровья путем улучшения пропаганды здорового образа жизни в школах, высших и средних специальных учебных заведениях, что позволит решить демографические, социальные и медицинские проблемы репродуктивного здоровья молодежи в целом.

\section{Выводы}

1. Проблемы репродуктивного поведения остаются повсеместно актуальными, причем их приоритетные составляющие в разных регионах мира зависят от этнических и культурных особенностей, 
а также от степени остроты медико-социальной ситуации в отдельно взятом государстве.

2. Социально-экономические преобразования последних десятилетий, происходящие в Таджикистане, бедность, трудовая миграция, нарушение семейных традиций, брачности, разводов значительно изменили традиционный уклад и образ жизни населения, что сильно отразилось на поведении, прежде всего молодежи, что требует разработки новой программы.

3. Комплексный, многоцелевой уровень профилактика ИППП является одной из актуальных задач системы здравоохранения, особенно на уровне работы ПМСП; в частности, это обусловлено частым отсутствием выраженной клинической симптоматики, высокой частотой смешанной инфекции и склонностью к развитию затяжных и хронических форм болезни.

\section{ЛИТЕРАТУРА \\ (III. 7-8 cM. BREFERENCES)}

1. Анализ заболеваемости и профилактики инфекций, передающихся половым путем // Отчет Министерства здравоохранения и социальной защиты населения Республики Таджикистан от 15 ноября 2018 г. № 5/8-720/4.

2. Гаибов А.Г. Основные аспекты охраны репродуктивного здоровья населения Республики Таджикистан / А.Г. Гаибов, М.Х. Ганиева, А.В. Вохидов // Вестник Авиценны. - 2016. - № 4. - С. 52-54.

3. Ганизода М.X. Стратегия улучшения репродуктивного здоровья населения Республики Таджикистан / М.Х. Ганизода, Дж. Г.Ашурова, Х.М.Гаибов // Здравоохранение Таджикистана. - 2019. - № 1. - С. 151-153.

4. Гоибзода М.А. Некоторые причины ранних браков и их социальные последствия в Таджикистане / М.А. Гоибзода, М.Х. Ганизода, А.Г. Гаибов, Н.Б. Лукьянов // Вестник Таджикского национального университета. - 2018. - № 1. - С. 199-203.

5. Глобальная стратегия Сектора здравоохранения ВО3 по инфекциям, передаваемым половым путём. 2016-2021. - Женева, 2016. - 64 с.

6. Киясов И.А. Современные тенденции заболеваемости инфекциями, передающимися половым путем, и пути их профилактики / И.А. Киясов, Ф.В. Хузиханов // Успехи современного естествознания. - 2015. - № 2. - С. 51-55.

\section{REFERENCES}

1. Analiz zabolevaemosti i profilaktiki infektsiy, peredayushchikhsya polovym putem. Otchet Ministerstva zdravookhraneniya i sotsialnoy zashchity naseleniya Respubliki Tadzhikistan ot 15 noyabrya $2018 \mathrm{~g}$ [Analysis of morbidity and prevention of sexually transmitted infections. Report of the Ministry of Health and Social Protection of the Republic of Tajikistan of November 15, 2018]. No. 5/8-720/4.

2. Gaibov A.G., Ganieva M.Kh., Vokhidov, A.V. Osnovnye aspekty okhrany reproduktivnogo zdorovya naseleniya Respubliki Tadzhikistan [Main Aspects of Reproductive Health of the Population of the Republic of Tajikistan]. Vestnik Avitsenny - Avicenna Bulletin, 2016, No. 4, pp. 52-54.

3. Ganizoda M.Kh. Strategiya uluchsheniya reproduktivnogo zdorovya naseleniya Respubliki Tadzhikistan [Strategy to Improve Reproductive Health of the Population of the Republic of Tajikistan]. Zdravookhranenie Tadzhikistana - Healthcare of Tajikistan, 2019, No. 1, pp. 151-153.

4. Goibzoda M.A. Nekotorye prichiny rannikh brakov i ikh sotsialnye posledstviya $\mathrm{v}$ Tadzhikistane [Some Causes of Early Marriage and Their Social Consequences in Tajikistan]. Vestnik Tadzhikskogo natsionalnogo universiteta - Bulletin of Tajik National University, 2018, No. 1, pp. 199-203.

5. VOZ. Globalnaya strategiya Sektora zdravookhraneniya VOZ po infektsiyam, peredavaemym polovym putyom. 2016-2021. [WHO Health Sector Global Strategy on Sexually Transmitted Infections. 2016-2021.] Zheneva, 2016. 64 p.

6. Kiyasov I.A. Sovremennye tendentsii zabolevaemosti infektsiyami, peredayushchimisya polovym putem, i puti ikh profilaktiki [Current trends in the incidence of sexually transmitted infections and ways to prevent them]. Uspekhi sovremennogo estestvoznaniya - Advances in modern nature science, 2015, No. 2, pp. 51-55.

7. Kegg S. Homosexual men, HIV, and sexual risk in 2001. Sexually transmitted infections, 2001, Vol. 77, No. 5, pp. 325-326.

8. Zetola N.M., Bernstein K.T., Wong E. Exploring the relationship between sexually transmitted diseases and HIV acquisition by using different study designs. JAIDS Journal of Acquired Immune Deficiency Syndromes, 2009, Vol. 15, No. 50, pp. 546-551.

\section{ХУЛОСА}

\section{Н.Т. Курбонов}

\section{ХУСУСИЯТХОИ РАФТОРИ ШАХВОНИИ ЧАВОНОН, КИ МУАЙЯНКУНАНДАИ АФЗОИШИ БЕМОРИХОИ ТАВАССУТИ АЛОҚАИ ЧИНСЙ ИНТИҚОЛЁБАНДА ДАР ЧУМХУРИИ ТОЧИКИСТОН}

Максади тахқиқот. Ошкор кардани хусусиятхои рафтори шахвонии чавонон, ки боиси афзоиши беморихои сироятии тавассути муносибатхои таносулй интиқолёбанда мегарданд.

Мавод ва усул. Мутобиқи анкетаи махсус тахиягардида пурсиши 500 нафар марду зани 
гурӯххои мухталифи ахолй аз синни 18 то 30 сола дар 4 нохияи тобеьи чумхурй гузаронида шуд. Хамзамон пурсиши ичтимой бо истифодаи усулй маъмулии интихобии гурууххои синну солй сурат гирифт. Чавоб ба саволхо бо истифодаи пакетхои MS OFFISE соли 2007 тахти коркарди оморй қарор дода шуд.

Натичахо. Муқаррар гардид, ки огохии пурсишкунандагон доир ба сироятхои тавассути муносибатхои чинсй интиқолшавандава роххои пешгирии он дар сатхи нихоят паст қарор дорад. Беш аз 21,0\% онхо мунтазам ба муносибатхои шахвонй машғул буда, хадди ақал хар шахси 5-ум хатари имконпазири сироятёбй ба ББРЧุИ, ВНМОро алоқаманд намемешуморад, тақрибан $17,0 \%$ чавонон чунин ақида доранд, ки хангоми мубтало ба ин беморихо танхо ба табибони шиноси худ, ё кормандони миёнаи тиббй мурочиат хоханд кард.
Хулоса. Дар шароити имрӯзаи зиндагонй проблемаи шахвонияти барвақт дар тамоми чахон нихоят мубрам мебошад. Хусусиятхои рафтори шахвонй аз шахвонияти барвақтй, инчунин мавчуд набудани омодагии хамачониба, аз чумла равонию эхсосот нисбат ба масъулияти оиладорй (издивоч, ақди никох) мебошад. Хамзамон, сатхи пасти дониш ва зарурияти воқифии наврасон ва чавоно дар мавриди оқибатхои манфии муносибатхои шахвонии хатарнок ба мушохида мерасад. Рафтори тазаккурй унсури чудонопазири саломатй буда, нихоят мухим баррасй мегардад ва дар хамбастагй ба дигар омилхои офияти ичтимоии инсонро таъмин менамояд.

Калима ва иборахои асосй: рафтори таззакурй (репродуктивй), чавонон, тарзи хаёт, омилхои хатар, сироят, тавассути муносибатхои чинси интиқолёбанда.

Г.С. Мамаджанова ${ }^{1}$, 3.К. Умарова ${ }^{2}$, Г.М.Саидмурадова ${ }^{3}$

\section{ВАКЦИНАЦИНАЦИЯ ПЕНТИВАЛЕНТНОЙ АКДС И АДС ВАКЦИНОЙ ЗДОРОВЫХ И ЧАСТО БОЛЕЮЩИХ ДЕТЕЙ}

${ }^{1}$ Кафедра детских болезней № 1, ГОУ «ТГМУ им. Абуали ибни Сино»

${ }^{2}$ Кафедра семейной медицины № 2, ГОУ «ТГМУ им. Абуали ибни Сино»

${ }^{3}$ Кафедра детских инфекций, ГОУ «ТГМУ им. Абуали ибни Сино»

Мамаджанова Гульнора Сидикжановна - к.м.н., доцент, заведующая кафедрой детских болезней №1 ГОУ «Таджикский государственный медииинский университет им. Абуали ибни Сино»; Тел.: +(992)918720903; E-mail: gulnora.mamadjanova@gmail.com

Цель исследования. Изучить вакичнированных здоровых и часто болеющих детей на формирование противодифтерийного иммунитета.

Материалы и методы исследования. Под нашим наблюдением было 50 практически здоровых и 92 часто болеющих детей. Всем детям проводилась вакиинации трехкратно пентавалентной вакциной, а также ревакичинация АКДС и АДС. Определяли формирование специифического противодифтерийного иммунитета через 6 месяцев, 1 год и 5 лет. Интерпретировали результат по окончательному значению оптической плотности уровни защиты: базовая -0,01 до 0,1; полная защчита - >0,1; долгосрочная защита - >1,0.

Результаты исследования их обсуждение. Через 6 месяцев напряжённость поствакиинального иммунитета как у здоровых, так и у больных детей составили высокий прочент: полная (>0,1) (45,8\%) и базовая защита (0,01 до 0,1) (31,0\%). Статистическая значимость снизилась через год: полная защчита (45,8\% против $12,1 \%, p<0,001)$, и повысилась отсутствие защчиты (2,6\% против 55,7\%, p<0,001), что указывало на выработку нестойкого иммунитета в связи, с чем была проведена ревакцинация АКДС и АДС. Через 5 лет после ревакцุинации, специфический иммунитет имел тенденцию к нарастанию как у здоровых детей, так и у больных.

Заключение. Для создания стойкого и продолжительного иммунитета при использовании «убитьх» вакцин и анатоксинов необходимы ревакцинирующие прививки через различные сроки после курса вакцинации часто болеющим детям, на что указывают данные базовой и полной защчиты.

Ключевые слова: дети, дифтерия, специфический иммунитет, 